\title{
Increasing incidence of early onset Type 1 (insulin-dependent) diabetes mellitus: a study of Danish male birth cohorts
}

\author{
A. Green ${ }^{1}$, P.K. Andersen ${ }^{2}$, A.J.Svendsen ${ }^{1}$ and K. Mortensen ${ }^{1}$ \\ ${ }^{1}$ Institute of Clinical Genetics, Odense University, ${ }^{2}$ Statistical Research Unit, University of Copenhagen, Denmark
}

\begin{abstract}
Summary. To provide information of the incidence trends of Type 1 (insulin-dependent) diabetes mellitus we performed a cohort study of a series of Danish male birth cohorts. All male livebirths in Denmark between 1 January 1949 and 31 December 1964, were investigated regarding the development of Type 1 diabetes during the first 20 years of life using the files of the Danish Conscript Board, supplemented by a search in the Danish National Registry of Deaths. Diagnosis was verified and clinical information obtained from medical records. The material is estimated to be more than $95 \%$ complete. A total of 1705 diabetic subjects were identified of whom 23 were not representative of idiopathic Type 1 diabetes. The cumulative rate of Type 1 diabetes develop-
\end{abstract}

ment during the first 20 years of life increased from 2.37 to 2.90 per 1000 for the first eight and last eight birth cohorts, respectively. A log-linear analysis of the incidence revealed significantly increasing incidence rates, independent of age effects, with a maximum in the late 1970 's. About $75 \%$ of the cases presented short duration of symptoms prior to diagnosis, and only very few cases were diagnosed incidentally. Cases were diagnosed relatively less frequently during summer months than during winter months.

Key words: Type 1 (insulin-dependent) diabetes mellitus, incidence, trends, seasonality, duration of symptoms.
The incidence of Type 1 (insulin-dependent) diabetes has been increasing at least in some parts of Europe during the last decades [1-8], occasionally with the character of an epidemic [9]. Furthermore, the incidence varies considerably throughout Europe [10-12]. These results strongly substantiate the existence of an environmental contribution to the aetiology of Type 1 diabetes [13]. We have previously demonstrated a gradual increase in Type 1 diabetes incidence among eight Danish male birth cohorts, observed with respect to the development of Type 1 diabetes during the first 20 years of life [3]. This analysis suggested that the increase in incidence plateaued during the mid-1970's. Because knowledge of incidence trends may provide clues to an understanding of the aetiology of Type 1 diabetes, we have extended the previously reported study to include a total of 16 male birth cohorts.

\section{Subjects and methods}

\section{Ascertainment and verification of cases}

According to the Danish constitution all male citizens must appear before a Conscript Board for a clinical examination and assessment prior to military or civil service. Subjects with a diagnosis of diabetes will inevitably be rejected with diabetes listed as the reason. Normally, the examination takes place at age 18-19 years but may, upon request, be postponed to age 26 years at the latest. However, it has been shown that persons with chronic diaseases such as diabetes tend to be examined on the earliest possible occasion [14]. For persons who develop diabetes after the Conscript Board Examination but before completing the military or civil service a reexamination is performed and the records are filed in the Conscript Registry. Accordingly, the registry provides data on patients with the diagnosis established up to age 20 years and in many instances higher ages.

From the files of the Danish National Conscript Registry we identified all males who were (1) born in Denmark between 1 January 1949 and 31 December 1964, and (2) were rejected by the Conscript Board due to a diagnosis of definite or possible diabetes. A supplementary search was performed in the Danish National Registry of Deaths to identify anyone from these birth cohorts who had died with diabetes being mentioned as a cause of death prior to Conscript Board examination.

For all cases hospital records were traced and scrutinized to verify and establish the time of diagnosis of diabetes; in three cases, this information was obtained from general practitioners. From the medical records, information was obtained on the duration of symptoms before diagnosis as well as on treatment and - whenever possible - conditions to which diabetes might be secondary.

As a diagnostic criterion for diabetes we required a clinical diagnosis of diabetes to be established by a physician. Patients treated permanently with insulin at latest 1 year after diagnosis and for 
Table 1. Overview of the study material

\begin{tabular}{|c|c|c|c|}
\hline & \multicolumn{3}{|l|}{ Cohort } \\
\hline & $1949-1956$ & $1957-1964$ & Total \\
\hline Liveborn males, $n$ & 320162 & 318556 & 638718 \\
\hline Initial study material & 884 & 1031 & 1915 \\
\hline \multicolumn{4}{|l|}{ Exclusion criteria } \\
\hline Not diabetes & 28 & 42 & 70 \\
\hline Born outside Denmark & 10 & 11 & 21 \\
\hline Diagnosed after age 20 years & 77 & 42 & 119 \\
\hline Sub total & 769 & 936 & 1705 \\
\hline \multicolumn{4}{|l|}{ Excluded from analysis } \\
\hline $\begin{array}{l}\text { Not permanent insulin } \\
\text { treatment }\end{array}$ & 7 & 8 & 15 \\
\hline $\begin{array}{l}\text { Diabetes secondary to } \\
\text { steroid treatment }\end{array}$ & 1 & 3 & 4 \\
\hline Diabetes secondary to & & & \\
\hline other conditions & 2 & 2 & 4 \\
\hline Final study material & 759 & 923 & 1682 \\
\hline \multicolumn{4}{|l|}{ Cumulative incidence } \\
\hline$(0-20$ years $)$, per 1000 & 2.37 & 2.90 & 2.63 \\
\hline $1 \mathrm{SEM}$ & 0.09 & 0.10 & 0.06 \\
\hline
\end{tabular}

Table 2. Regression analysis of incidence (log scale). Model: In (incidence) $=$ constant + age effect + time effect

\begin{tabular}{lll}
\hline Variable & Estimated effect & Standard error \\
\hline Constant & -11.497 & 0.577 \\
Age & & \\
$0-3$ years & $(0)$ & - \\
4-7 years & 0.361 & 0.102 \\
8-11 years & 0.413 & 0.106 \\
12-15 years & 0.690 & 0.109 \\
16-19 years & 0.283 & 0.121 \\
Calendar time & & \\
1949-1952 & $(0)$ & - \\
$1953-1956$ & 1.732 & 0.594 \\
$1957-1960$ & 2.006 & 0.587 \\
$1961-1964$ & 2.234 & 0.586 \\
$1965-1968$ & 2.285 & 0.586 \\
$1969-1972$ & 2.429 & 0.588 \\
$1973-1976$ & 2.548 & 0.590 \\
$1977-1980$ & 2.594 & 0.592 \\
$1981-1984$ & 2.329 & 0.610 \\
\hline
\end{tabular}

whom no mention was found in the medical records of diseases or conditions to which diabetes might be secondary were considered to be representative of idiopathic Type 1 diabetes.

The methods have been described previously $[3,14]$ for the first eight birth cohorts, and it has been estimated that this ascertainment method is more than $95 \%$ complete [14].

\section{Population data}

Data on the number of liveborn males from the cohorts under study were obtained from official statistical reports (Danmarks Statistik). Also, it has been possible from these sources to assess the number of deaths and emigrations at each 1-year age level in the study population. After subtraction of all subjects who have emigrated before age 20 years we have estimated the number of person-years at risk of diabetes for various age and calendar time intervals [15]. This was done to outweigh the omission of diabetic individuals who might have emigrated before the age of conscription.

\section{Statistical analysis}

The incidence was analysed in a log-linear model [16] using the GENSTAT programming language [17] to study the effects of age and calendar time. The analysis assumes constant incidences within cells of age and calendar time intervals of 4-year lengths. The full model including all possible interaction terms between age and calendar time was reduced to a model with only main effects of age and time using the likelihood ratio test statistic. Subsequently, seasonality of diagnosis and symptom duration were also included in the analysis, and the distribution of seasonality and symptom duration within age intervals were analysed by conventional chi-square statistics (based on the log-linear models).

\section{Results \\ Overview of the study material}

The initial search in the files of the Conscript Board identified a total of 1915 potential study individuals (Table 1). A total of 210 persons were excluded; 119 had diabetes diagnosed later than the 20th birthday, 21 were born outside Denmark, and 70 persons suffered from other diseases (renal glucosuria, malabsorption or other metabolic diseases belonging to the same category of rejection as diabetes). After reduction by cases not fulfilling the inclusion criteria 1705 subjects remained. However, 23 cases have been excluded from analysis since they are probably not representative of idiopathic Type 1 diabetes; the four cases believed to be secondary to other conditions represented congenital pancreas aplasia (one case), pancreatitis (two cases) and cystic fibrosis (one case). Of the remaining 1682 patients, 30 were identified exclusively from the Danish National Registry of Deaths.

Table 1 also shows the cumulative incidence rates, which can be interpreted as the risk of developing Type 1 diabetes from birth to age 20 years. It should be noted, however, that these estimates do not account for possible incidence variations over calendar time.

\section{Regression analysis of the Type 1 diabetes incidence}

In the log-linear regression analysis of the Type 1 diabetes incidence we first tested the hypothesis of reduction from the full model (including interactions between age and calendar time) to a model with independent effects of age and calendar time. This was clearly accepted, the likelihood ratio test statistic being 6.59 ( $p=0.88$ when evaluated in a chi-square distribution with 12 degrees of freedom, ${ }^{\mathrm{df}}$ ). Further reduction was not possible. The estimated effects of calendar time and age in the final model are shown in Table 2; for example, the incidence for 12-15-year-old subjects during the period 1973-1976 is estimated as $\exp (-11.497+0.690+2.548)=25.9$ per 100,000 person-years.

The resulting estimates of the incidences according to age intervals and calendar time are shown in Figure 1. On the natural scale, the estimated effects of calendar time demonstrates that the incidence of Type 1 diabetes doubled from the beginning of the 1950's during the next 30 years. 
A

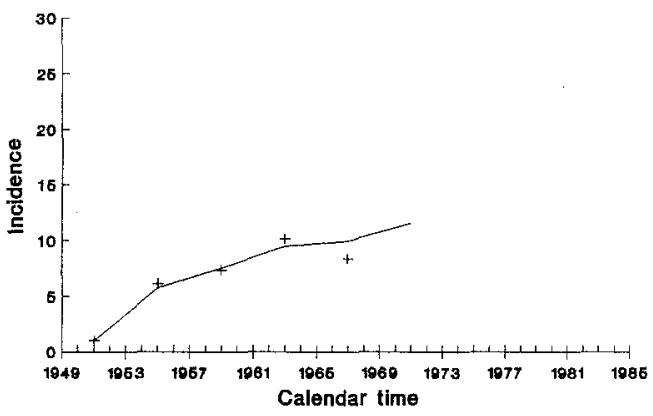

C

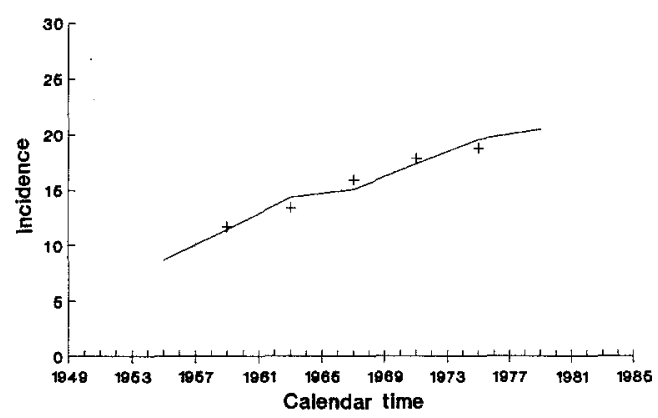

E

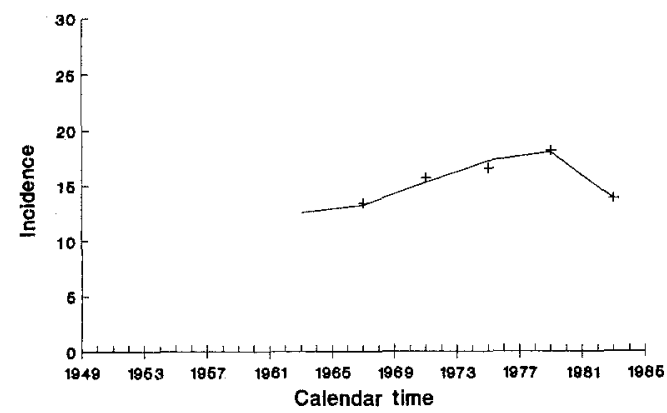

B

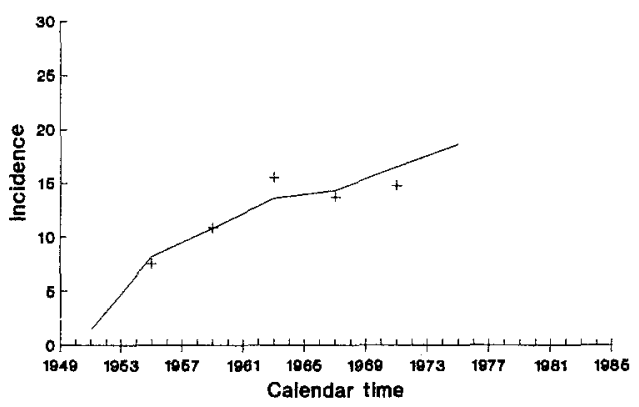

D

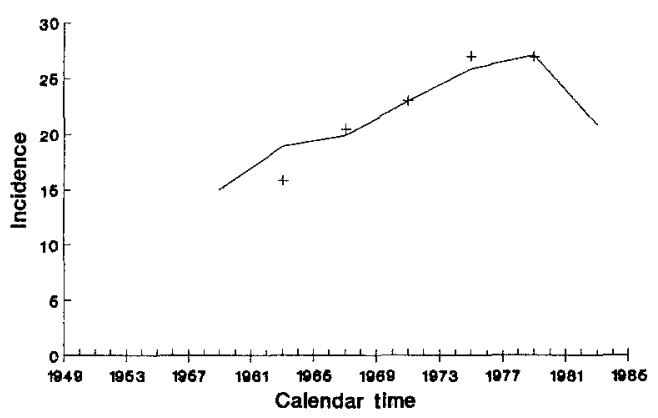

Fig.1A-E. Estimated incidence rates of Type 1 (insulin-dependent) diabetes mellitus (per 100,000 person-years) according to age and calendar time. $\mathbf{A}$, age group $0-3$ years; $\mathbf{B}$, age group $4-7$ years; $\mathbf{C}$, age group $8-11$ years; $\mathbf{D}$, age group $12-15$ years; $\mathbf{E}$, age group $16-19$ years. + : Observed incidence rates; --: Estimated incidence rates (model from Table 2)

\section{Analysis of seasonal variation at diagnosis}

The distribution of seasonality at diagnosis of Type 1 diabetes is shown in Table 3, specified according to age at diagnosis. The distribution of seasonality differed between the four age groups by borderline statistical significance only (chi-square: $15.36, \mathrm{df}=9, p=0.08$ ). However, whereas the youngest age groups revealed no statistically significant seasonal variation, when analysed separately both the age groups 10-14 and 15-19 years showed significant variations with relatively fewer cases diagnosed during summer ( $p<0.00001$ and $p<0.025$, respectively).

\section{Analysis of symptom duration}

The association between duration of symptoms prior to the establishment of diagnosis and age at diagnosis is shown in Table 4 . Overall, $21.4 \%$ of the cases had symp- toms for more than 2 months whereas only $2.8 \%$ had no symptoms at all; these cases were typically detected during routine urine examinations. The distribution of symptom duration varied significantly by age group (chi-square: 19.21 , $\mathrm{df}=6, p<0.005$ ), the significance being caused by relatively more cases with short duration $(84.5 \%)$ in the youngest age group.

\section{Discussion}

Our study has confirmed that the incidence of early onset Type 1 diabetes in Denmark is relatively high, compared with other regions in Europe [10-12]. Furthermore, we have found that in most cases the onset of diabetes is preceeded by a short period with symptoms when assessed from routinely recorded data in the medical records; in only $1-2 \%$ of the patients was the diagnosis established by 
Table 3. Seasonality of diagnosis of diabetes by age

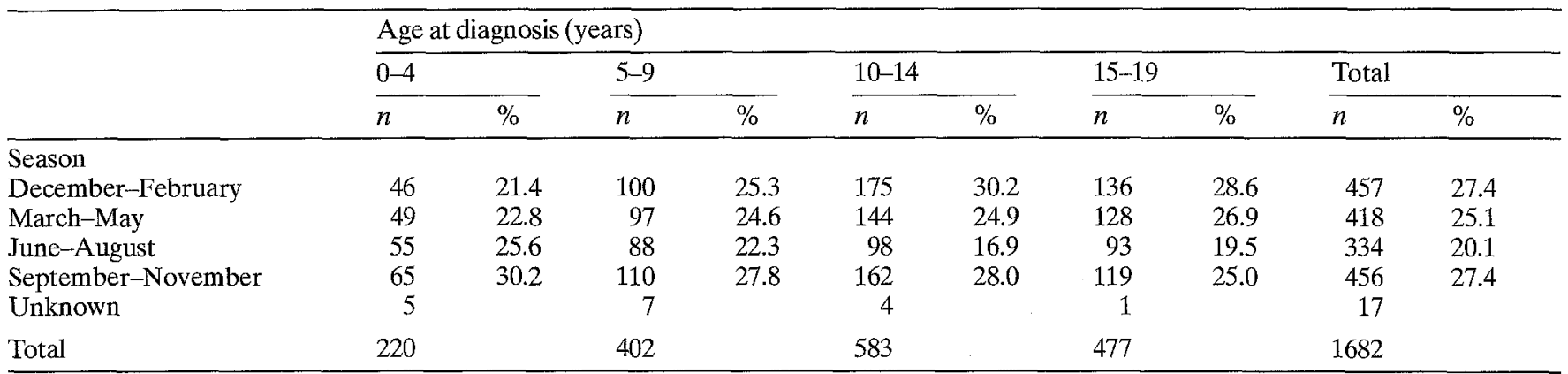

Table 4. Distribution of symptom duration

\begin{tabular}{|c|c|c|c|c|c|c|c|c|c|c|}
\hline \multirow[t]{3}{*}{ Duration of symptoms } & \multicolumn{10}{|c|}{ Age at diagnosis (years) } \\
\hline & \multicolumn{2}{|l|}{$0-4$} & \multicolumn{2}{|l|}{$5-9$} & \multicolumn{2}{|c|}{$10-14$} & \multicolumn{2}{|c|}{$15-19$} & \multicolumn{2}{|l|}{ Total } \\
\hline & $n$ & $\%$ & $n$ & $\%$ & $n$ & $\%$ & $n$ & $\%$ & $n$ & $\%$ \\
\hline Less than 2 months & 175 & 84.5 & 300 & 76.7 & 428 & 75.1 & 337 & 72.0 & 1240 & 75.8 \\
\hline No symptoms & 4 & 1.9 & 4 & 1.0 & 18 & 3.2 & 20 & 4.3 & 46 & 2.8 \\
\hline Sub total & 207 & & 391 & & 570 & & 468 & & 1636 & \\
\hline
\end{tabular}

routine examination without clinical symptoms. We found that the diagnosis of Type 1 diabetes was established relatively more frequently in winterly than in summer, confirming results from other studies [4, 7, 18-29]. It remains to be determined whether the seasonal variation reflects higher probability of precipitation of clinical disease among susceptible individuals or whether the patients and their families are more alert to symptoms during the dark months.

The principal aims of our study were to characterize the secular trend in the incidence of Type 1 diabetes. In the analysis of the first part of these cohorts we found a curvilinear increasing trend in the Type 1 diabetes incidence with a possible plateau about the mid-1970's. This trend has been confirmed in the extended study even though it was impossible to describe the calendar time effect by a simple equation. Nevertheless, the calendar time effects clearly demonstrate that the incidence apparently reached a maximum in the late 1970 's. Furthermore, our analysis has suggested that the calendar time effects apply equally to all age groups studied.

Because the present study material is delineated as a classic cohort it is impossible to determine whether the calendar time effects might be confounded by particular cohort effects. However, recent studies from Sweden [6] and Finland [8] have investigated this aspect and found no evidence of cohort effects. Both studies also identified a gradually increasing incidence without any interaction between age and calendar time, and with similar trends for both sexes. Accordingly, even though the present study has been restricted by design to males, our conclusions can probably be generalised for females as well.

The causation of the increasing trend in Type 1 diabetes incidence is unknown. Possibly, the incidence increase might be explained by increasing number of genes conferring susceptibility to Type 1 diabetes in the popula- tions in which Type 1 diabetic patients have improved survival [30] and therefore possibly also improved reproductive capacity. This explanation is unlikely for several reasons. First, the most simple genetic models of the HLA-conferred susceptibility to Type 1 diabetes involve a disease gene with high frequency and low penetrance, implying that most gene carriers are unaffected heterozygotes [31]. Second, even in "high risk" populations, only about $10 \%$ of newly-diagnosed children with Type 1 diabetes have affected mothers or fathers [32], implying that most cases are offspring of healthy individuals. Accordingly, the additional susceptibility genes, introduced because of improved fertility and survival among patients with Type 1 diabetes, must have represented only a small and probably insignificant contribution to the pool of susceptibility genes.

No likely candidates of aetiologically important factors in the environment have so far been identified with certainty. However, the existence of both an increasing trend in incidence and of a ten-fold difference between lowest and highest recorded incidence in Europe [12] illustrates the potential value of comparative case-control studies across populations to identify the environmental determinants of Type 1 diabetes.

Acknowledgements. The study has been supported by grants from Diabetesforeningen (the Danish Diabetes Association) and Smith \& Company's Fond.

\section{References}

1. Hägglöf B, Holmgren G, Wall S (1982) Incidence of insulindependent diabetes mellitus among children in a North-Swedish population 1938-1977. Hum Hered 32: 408-417

2. Patterson CC, Thorogood M, Smith PG, Heasman MA, Clarke JA, Mann JI (1983) Epidemiology of Type 1 (insulin-dependent) 
diabetes in Scotland 1968-1976: evidence of an increasing incidence. Diabetologia 24: 238-243

3. Green A, Andersen PK (1983) Epidemiological studies of diabetes mellitus in Denmark: 3. Clinical characteristics and incidence of diabetes among males aged 0 to 19 years. Diabetologia $25: 226-230$

4. Joner G, S $\emptyset$ vik O (1989) Increasing incidence of diabetes mellitus in Norwegian children 0-14 years of age 1973-1982. Diabeto logia 32: 79-83

5. Burden AC, Hearnshaw JR, Swift PGF (1989) Childhood diabetes mellitus: an increasing incidence. Diab Med 6:334-336

6. Nyström L, Dahlquist G, Rewers M, Wall S (1990) The Swedish Childhood Diabetes Study. An analysis of the temporal variation in diabetes incidence 1978-1987. Int J Epidemiol 19: 141-146

7. Soltész G, Madácsy L, Békefi D, Dankó I, the Hungarian Childhood Diabetes Epidemiology Group (1990) Rising incidence of Type 1 diabetes in Hungarian children (1978-1987). Diab Med 7: 111-114

8. Tuomilehto J, Rewers M, Reunanen A et al. (1991) Increasing trend in Type 1 (insulin-dependent) diabetes mellitus in childhood in Finland. Analysis of age, calendar time and birth cohort effects during 1965 to 1984. Diabetologia 34: 282-287

9. Rewers M, LaPorte RE, Walczak M, Dmochowski K, Bogaczynska E (1987) Apparent epidemic of insulin-dependent diabetes mellitus in Midwestern Poland. Diabetes 36: 106-113

10. Diabetes Epidemiology Research International Group (1988) Geographic patterns of childhood insulin-dependent diabetes mellitus. Diabetes 37:1113-1119

11. Rewers M, LaPorte RE, King H, Tuomilehto J (1988) Trends in the prevalence and incidence of diabetes: insulin-dependent diabetes mellitus in childhood. World Health Statist Quart 41: 179-189

12. Green A, The EURODIAB Subarea A Study Group (1990) Geographical distribution of childhood Type I (insulin-dependent) diabetes in Europe: The EURODIAB Subarea A Study. Diabetologia 33: A17 (Abstract)

13. Green A (1990) The role of genetic factors in development of insulin dependent diabetes mellitus. In: Bakkeskov S, Hansen B (eds) Human diabetes. Genetic, environmental and autoimmune etiology. Current topics in microbiology and immunology, Vol. 164. Springer, Berlin Heidelberg New York, pp 3-16

14. Green A, Hauge M, Holm NV, Rasch LL (1980) Epidemiological studies of diabetes mellitus in Denmark. I. A case finding method based on the National Service Conscript Registry. Diabetologia 19: 355-358

15. Andersen PK, Green A (1985) Evaluation of estimation bias in an illness-death-emigration model. Scand J Statist 12: 63-68

16. Breslow NE, Day NE (1987) Statistical methods in cancer research, Vol. II. The design and analysis of cohort studies. IARC, Lyon

17. GENSTAT 5 Committee of the Statistics Department, Rothamstead Experimental Station (1989) GENSTAT 5 Reference Manual. Oxford Science Publications, Oxford

18. Christau B, Kromann H, Andersen OO et al. (1977) Incidence, seasonal and geographic patterns of juvenile-onset insulin-dependent diabetes mellitus in Denmark. Diabetologia 13:281-284
19. Sterky G, Holmgren G, Gustavson KH et al. (1978) The incidence of diabetes mellitus in Swedish children 1970-1975. Acta Pædiatr Scand 67: 139-143

20. Gray RS, Duncan LJP, Clarke BF (1979) Seasonal onset of insulin dependent diabetes in relation to sex and age at onset. Diabetologia 17:29-32

21. Durruty P, Ruiz F, Garcia de los Rios M (1979) Age at diagnosis and seasonal variation in the onset of insulin-dependent diabetes in Chile (southern hemisphere). Diabetologia 17:357-360

22. Fishbein HA, LaPorte RE, Orchard TJ, Drash AL, Kuller LH, Wagener DK (1982) The Pittsburgh insulin-dependent diabetes mellitus registry: seasonal incidence. Diabetologia 23: 83-85

23. Gleason RE, Kahn CB, Funk IB, Craighead JE (1982) Seasona] incidence of insulin-dependent diabetes (IDDM) in Massachusetts, 1964-1973. Int J Epidemiol 11: 39-45

24. Reunanen A, Åkerblom HK, Käär M-J (1982) Prevalence and ten-year (1970-1979) incidence of insulin-dependent diabetes mellitus in children and adolescents in Finland. Acta Pædiatr Scand 71:893-899

25. Hours M, Fabry J, Siemiatycki J, Francois R (1984) Diabète insulino-dépendant juvénile. Etude descriptive dans le département du Rhône. Rev Epidém et Santé Publ 32: 107-112

26. Dahlquist G, Blom L, Holmgren G et al. (1985) The epidemiology of diabetes in Swedish children 0-14 years - a six-year prospective study. Diabetologia 28: 802-808

27. Schober $E$, Frisch $H(1988)$ Incidence of childhood diabetes mellitus in Austria 1979-1984. Acta Pædiatr Scand 77: 299-302

28. Calori G, Gallus G, Garancini P, Repetto F, Micossi P (1990) Identification of the cohort of Type 1 diabetes presenting in Lombardy in 1983 -1984: a validated assessment. Diab Med 7: 595-599

29. Serrano Rios M, Moy CS, Serrano RM et al. (1990) Incidence of Type 1 (insulin-dependent) diabetes mellitus in subjects 0-14 years of age in the Comunidad of Madrid, Spain. Diabetologia 33: $422-424$

30. Green A, Borch-Johnsen K, Andersen PK et al. (1985) Relative mortality of Type 1 (insulin-dependent) diabetes in Denmark: 1933-1981. Diabetologia 28: 339-342

31. Green A, Svejgaard A, Platz P et al. (1985) The genetic susceptibility to insulin-dependent diabetes mellitus (IDDM): combined segregation and linkage analysis. Genet Epidemiol 2: 1-15

32. Dahlquist G, Blom L, Tuvemo T, Nyström L, Sandström A, Wall S (1989) The Swedish Childhood Diabetes Study - results from a nine year case register and a one year case-referent study indicating that Type 1 (insulin-dependent) diabetes mellitus is associated with both Type 2 (non-insulin-dependent) diabetes mellitus and autoimmune disorders. Diabetologia 32:2-6

Received: 22 August 1991

and in revised form: 23October 1991

Dr. A. Green

Department of Medical Genetics

Winsløwparken 15

DK-5000 Odense C

Denmark 